\title{
Shoulder Pain — Where Are We Now?
}

\section{Karen Walker-Bone, BM, FRCP, PhD, Hon FFOM ${ }^{1,2, *}$ Danielle AWM van der Windt, $P h D^{3}$}

\author{
Address \\ ${ }^{*}, 1$ MRC Versus Arthritis Centre for Musculoskeletal Health and Work, University of \\ Southampton, Southampton, UK \\ Email: kwb@mrc.soton.ac.uk \\ ${ }^{2}$ MRC Lifecourse Epidemiology Unit, Southampton General Hospital, University of \\ Southampton, Tremona Road, Southampton, S016 6YD, UK \\ ${ }^{3}$ School of Medicine, Primary Care Centre Versus Arthritis, Keele University, Keele, \\ UK
}

Published online: 5 August 2021

(C) The Author(s) 2021

This article is part of the Topical Collection on Pain in Rheumatology

Keywords Shoulder pain - Chronic shoulder pain - Imaging of the shoulder - Risk factors - Treatment of shoulder pain

\begin{abstract}
Purpose of Review Shoulder pain is common and costly. For the past century, diagnosis and management has been based upon presumed patho-anatomical abnormalities. With the evolution of imaging techniques and new insight about the causes of musculoskeletal pain, this review evaluates the evidence that a patho-anatomical approach remains justified.

Recent Findings Imaging modalities have developed considerably but, so far, have only proven value in evaluating full thickness rotator cuff tears prior to surgery. Correlation between imaging findings and symptoms is otherwise poor, with limited evidence of the value and impact of imaging for decision-making. Much of shoulder pain is chronic and few people have single-site musculoskeletal pain. Pain studies suggest that chronic shoulder pain is associated with both central and peripheral pain sensitisation. Moreover, functional MRI points to an effect of cognitive affective pain processing rather than nociception. Few of the established therapies, medical or surgical, that treat the presumed patho-anatomical cause have been shown to have lasting benefit.

Summary Much of the evidence suggests that shoulder pain is more similar than different from mechanical low back pain. For most people with shoulder pain, the best approach might well be de-medicalisation, support to (self)manage pain, emphasis on retaining movement and identifying adverse beliefs and risk factors for disability and chronicity. Approaches like this are currently being evaluated and more research is desperately required.
\end{abstract}




\section{Introduction}

Shoulder pain is common, with an estimated annual incidence of 0.9 to $2.5 \%$ [1] and point prevalence of $18-26 \%$ [2-5]. It is reported to be the third most common musculoskeletal symptom presenting for health care, making up an estimated $4 \%$ of annual consultations by adults in UK primary care [6,7]. Unfortunately, shoulder pain is also difficult to diagnose and to treat effectively $[8,9 \bullet]$. Although several interventions appear to offer short-term relief, up to $50 \%$ of people remain symptomatic 18 months after presentation [10] and the course and prognosis may follow a relapsing-remitting pattern, making its assessment at a single time point potentially misleading. Symptoms can be disabling, affecting sleep and performance of daily activities both at home and in the workplace $[11,12]$. Shoulder pain results in a substantial economic burden including healthcare costs [13], and impacts on work participation including reduced productivity, increased sickness absence, and higher risks of early retirement or permanent work disability [14-17]. The relationship with work disability is set to become increasingly important as governments take measures to encourage people to work to older ages because shoulder pain is strongly correlated with age (prevalence rate amongst adults aged $>70$ years has been estimated as $21 \%$ [18]). This review will explore the known risk factors for shoulder pain and its differential diagnosis, consider the evidence surrounding the effectiveness of separation of shoulder pathologies by patho-anatomical diagnosis, and review the evidence underpinning current therapeutic modalities. Ultimately, we question whether a new approach is needed to the diagnosis and management of shoulder pain.

\section{Risk factors for shoulder pain}

\section{Differential diagnosis of shoulder pain}

Shoulder pain does not always arise directly from the shoulder joint complex and can also be referred, or be the presenting feature of systemic disease (Figure 1) (reprinted with permission from Rees J and Carr A). Despite the plethora of differential diagnoses however, the vast majority of shoulder pain is regional pain which has hitherto widely been attributed to localised pathology 
Table 1. Risk factors for shoulder pain

\begin{tabular}{lll}
\hline Type of risk factor & Specific factor & Reference(s) \\
Socio-demographic & Older age & Sansone et al. [73] \\
& Female gender & Miranda et al. [20] \\
Personal & Obesity & Luime et al. [74] \\
& Cigarette smoking & Ryall et al. [75] \\
Clinical & Diabetes mellitus & Shah et al. [76] \\
& Stroke & Anwer et al. [77] \\
Psychological & Emotional distress & Nahit et al. [78], Bovenzi et al. [79] \\
& Somatisation & Sarquis et al. [80] \\
Occupational & Heavy physical load (heavy lifting, & Beach et al. [81], Andersen et al. [82], Bernard \\
& pushing, pulling, carrying, holding) & [20] \\
& Working with arms raised above shoulder height & Harkness et al. [83] \\
& Repetitive work & Leclerc et al. [84], Descatha et al. [85] \\
& Exposure to vibration & Bernard [20] \\
& Working in awkward postures & (trunk flexed, twisted postures) \\
& Psychosocial work environment & Miranda et al. [19]
\end{tabular}

\section{Imaging and shoulder pain}

affecting the peri-articular soft tissues (ligaments, muscles, capsule, tendons, labrum, bursae). A detailed discussion of the referred pain syndromes, systemic diseases, and articular pathologies is outside the scope of this review, which will focus instead on the so-called soft tissue conditions as the cause of the majority of shoulder pain in the population.

For the last 100 years, clinicians and researchers have attempted to better understand the causes and burden of localised shoulder pain using pathoanatomical classification systems which separated different types of shoulder pathology [23-25]. Patho-anatomical entities (otherwise known as "specific shoulder conditions") which were described include the following: impingement; rotator cuff tears; adhesive capsulitis; bicipital tendinopathy; bursitis; calcific tendinopathy; instability; and labral tears. In clinical medicine, separation of different patho-anatomical diseases is important when it defines conditions with a different cause, prognosis, or response to treatment (e.g. "pulmonary tuberculosis" versus "chest infection"). As this review considers the development of imaging for shoulder pain, our developing understanding of the importance of multi-site musculoskeletal pain, and increasing knowledge of the brain changes which accompany acute and chronic pain, the reader is encouraged to consider to what extent the patho-anatomical separation of shoulder pain stands up.

As imaging techniques have developed, they have been employed to a growing extent amongst people with shoulder pain. In particular, X-ray, magnetic 


\section{Diagnosis of Shoulder problems in Primary Care:}

\section{Guidelines on treatment and referral}

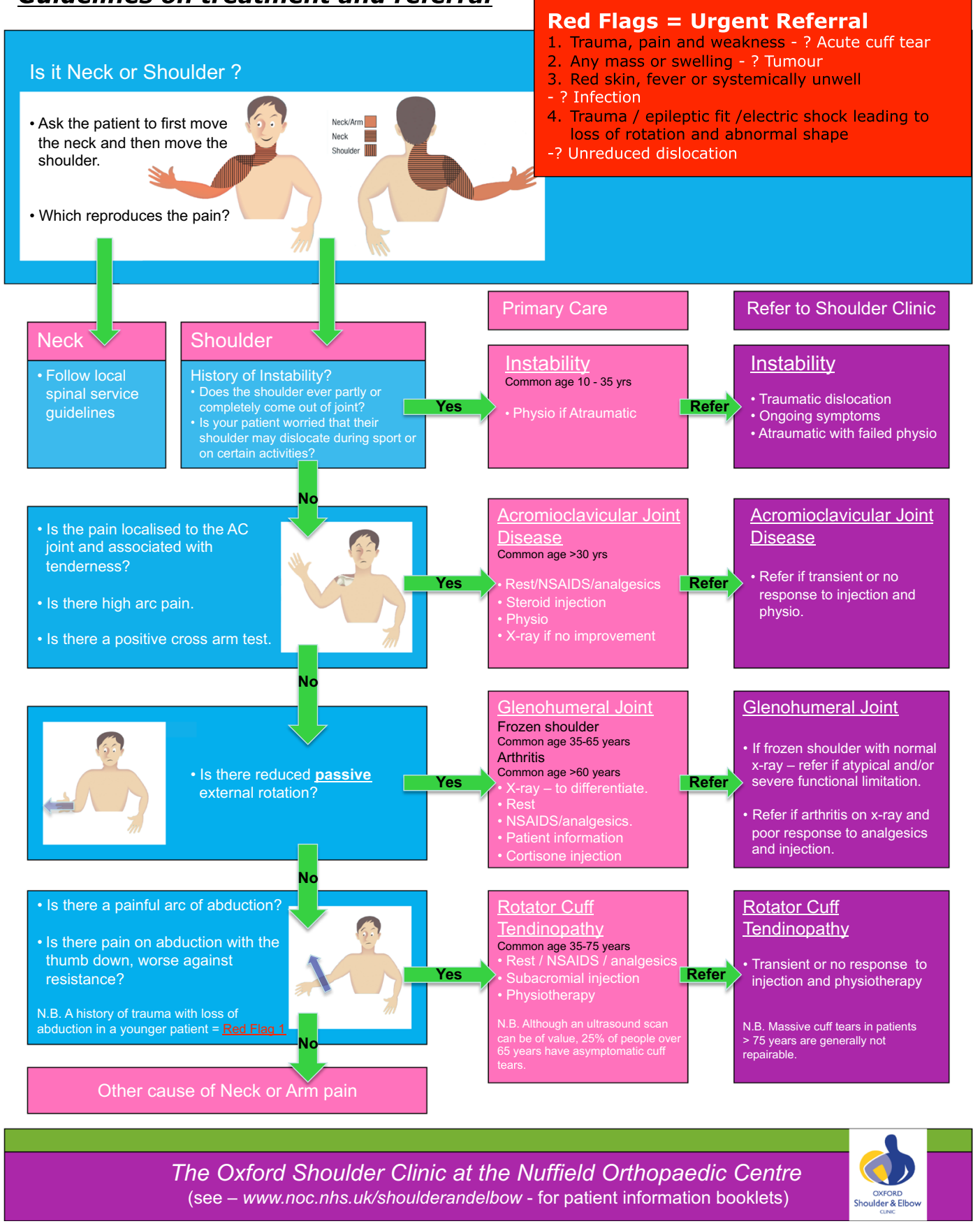

Figure 1. Schematic for the diagnosis of shoulder problems in primary care. (Reproduced with kind permission of Rees JL, and Carr AJ).

resonance imaging (MRI) scanning, magnetic resonance arthrography (MRA), and ultrasound scanning are commonly used modalities whilst bone scintigraphy, PET scanning, and CT arthrography are less commonly used. MRI, MRA, 
and ultrasound have been shown to accurately detect some patho-anatomical abnormalities such as rotator cuff (RC) tears, tendinopathies, and subacromial bursitis $[26,27]$, and to do so more accurately than clinical examination. In the planning of surgery for rotator cuff tears, a Cochrane review found evidence suggesting that any of MRI, MRA, or ultrasound could equally be used for detection of full thickness tears amongst people with shoulder pain for whom surgery is being considered [28]. However, the authors found that neither MRI nor ultrasound had good sensitivity for detecting partial thickness tears, with ultrasound sensitivity possibly considerably poorer than that of MRI. The authors were clear however that their findings related only to pre-operative imaging for acute or severe shoulder pain. Importantly, a US study which investigated patients with rotator cuff tears undergoing operative and nonoperative treatment found that pain and functional status were not associated with any MRI features including tear size and thickness; fatty infiltration; and muscle atrophy [29]. It is important to realise that rotator cuff tears are also common in those without shoulder pain (prevalence 4 to $51 \%$ increasing with age) [30,31], and do not always correlate with symptom severity [32-34].

For the majority of shoulder pain for which surgery is not considered, the role of imaging is far from well-established and surveys of practice in Australia [8] and the UK [9] showed marked heterogeneity of what primary care doctors respond they would request in response to clinical vignettes and a heavy reliance upon imaging "in support of their clinical diagnosis". It is interesting to note that use of ultrasound for shoulder pain has increased 10-fold in Australia even without any clear indication of its role [8]. In one recent trial in which patients were randomised to have ultrasound-tailored treatment of their shoulder pain versus usual care, no statistically significant difference was seen between rates of recovery in either arm [35]. Indeed, a systematic review of the relationship between shoulder symptoms and all imaging modalities concluded that, although this was a conflicting literature, there was no significant association between most imaging features and symptoms in the high-quality, cross-sectional studies [36••]. They did however find low-quality evidence that enhancement of the joint capsule on MRI and increased uptake on PET were associated with symptoms in adhesive capsulitis. Additionally, they found convincing evidence from high-quality longitudinal studies that enlarging ro-

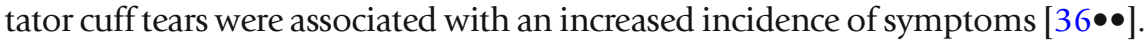

In a separate study, Tran and colleagues analysed the abnormalities found on ultrasound scans from 3000 people referred because of shoulder pain from primary care [37•]. Instead of classifying on the basis of any pre-existing systems of classification, they used statistical latent class analysis to develop clusters from the ultrasound findings. The analysis yielded four distinct clusters, which had only some resemblance to traditional patho-anatomical ones: (a) bursitis with minimal inflammation elsewhere; (b) bursitis with extensive inflammation elsewhere; (c) rotator cuff tears; and (d) limited pathology [37•]. Amongst the 777 of these 3000 individuals who completed questionnaires, they found that people in groups (a) and (b) were most likely to have received steroid injections, those in group (c) most likely to have been treated surgically and that those in group (d) who underwent surgery reported poor outcomes. Notably, the shoulder pain and disability index scores were lowest in group (d) and highest in group (c). 
Overall therefore, imaging has facilitated comparison of shoulder symptoms with presumed patho-anatomical abnormalities but imaging-detected structural changes increase with age and are common in asymptomatic subjects [38]. Therefore, incidental pathology identified on scans may lead to over-diagnosis, increase concerns for patients, and potentially lead to unnecessary referrals for surgical opinion. Moreover, not all imaging modalities available allow visualisation of all of the shoulder complex. In particular, the most widely used imaging modalities: $\mathrm{x}$-ray and ultrasound offer rather limited visualisation. Xrays offer excellent views of the bones and joints, and the position of the humeral head and can help to exclude calcific tendonitis but fail to image normal soft tissues. Ultrasound can effectively identify full-thickness rotator cuff tears and be useful in planning surgical intervention and can identify inflammation but otherwise there is currently limited evidence for their utility in diagnosis and management of shoulder pain. Altogether currently therefore, imaging has not done much to build confidence in the presumption that our pre-defined patho-anatomical abnormalities represent separate diseases with different causes, responses to treatment, or prognoses.

\section{Multisite musculoskeletal pain}

Over a decade or more now, there has been growing recognition that musculoskeletal pain rarely occurs only at a single anatomical site. One study, for example, showed that only $16.8 \%$ of responders reported single-site pain whilst $53 \%$ reported pain at $>1$ site [39]. In fact, a number of population-based studies have found that more than half of their population reported multi-site pain [40-42]. Even amongst people at work in 24 countries across 5 continents, multi-site pain was considerably more common than single-site pain [43]. It is noteworthy that most of the early epidemiological literature which described the risk factors for incidence and prevalence of shoulder pain, focused on people defined by saying "yes" to pain in one or both shoulders, and did not include any consideration of pain at other anatomical sites. However, it is becoming clear that presence of pain at other anatomical sites is of relevance

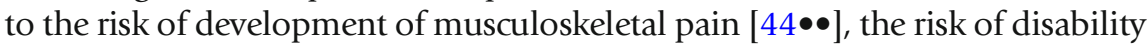
from the pain $[39,45 \bullet, 46]$, the response of the pain to treatment and its prognosis $[45 \bullet, 47 \bullet]$. Several cohort studies of people presenting with shoulder pain in primary care have also reported poorer outcomes of pain and function, and lower recovery rates after 3-12 months in those with musculoskeletal pain at other sites [48-51]. Therefore, extrapolating from this evidence, the relatively poor prognosis reported for shoulder pain might usefully be at least partly explained by the presence/absence of pain at other musculoskeletal sites. More research is required which takes multisite pain into account in exploring response to treatment and/or prognosis.

\section{Shoulder pain and the brain}

Some further insight can be gleaned from investigations of pain sensitivity amongst people with shoulder pain. In a group of adults aged 18-85 years awaiting arthroscopic shoulder surgery with unilateral shoulder pain who did not report pain $>3$ months at any other anatomical site, and a group of healthy 
controls without shoulder pain, features of both peripheral and central pain sensitisation in relation to painful stimuli including pressure pain and thermal sensitivity were demonstrated [52]. Interestingly, some shoulder pain subjects demonstrated peripheral and central pain sensitisation whilst in others, the pattern was more central or more peripheral and the authors could not "explain" these variable patterns with any data that they had collected. Their findings were consistent with those seen in other unilateral musculoskeletal conditions, and the authors suggested that the standard treatment approaches for shoulder pain that focus on the peripheral stimulus (steroid injections, physiotherapy) would have limited effectiveness for the management of people with central sensitisation patterns.

Additionally, a recent study amongst patients aged 45-65 years with unilateral chronic shoulder pain (lasting $>6$ weeks but $<24$ months) used functional MRI of the brain to assess pain responses [53•]. The authors found that, compared with age- and sex-matched controls, individuals with chronic shoulder pain had changes on functional MRI that they interpreted as showing evidence that the experience of chronic shoulder pain amongst these patients may be mainly associated with cognitive affective pain processing, and perception modulation, rather than nociception [53•]. This study too provides evidence to suggest that chronic shoulder pain is perpetuated by central pain pathways even if the original cause of the shoulder problem was peripheral injury.

Further insight comes from a study by Jain and colleagues who explored predictors of pain and functional outcomes after surgery for rotator cuff tears [54•]. The authors found that none of socio-demographic characteristics; MRI findings (including tear size and muscle quality); shoulder strength; or variations in surgical techniques/performance of adjuvant surgical procedures predicted post-operative pain or function. However, they showed that preoperative beliefs expressing less fear-avoidance for physical activity and mild weekly alcohol consumption ( $1-2$ units), as compared with $<3$ units/monthly, were the only factors which predicted better functional outcomes.

Taken together therefore, there is growing evidence for a role of central pain processing and perhaps other factors including beliefs, expectations, perceptions, somatisation, mood and affect both in the development of shoulder pain, and in its persistence to chronicity. What however is currently less clear is to what extent, if any, there is interaction between patho-anatomical entities and these factors.

\section{Treatment of shoulder pain}

Table 2 summarises a synthesis of the results from systematic reviews exploring the effectiveness of different treatment modalities for shoulder pain. Although more than 400 trials have been published, most studies have included a small number of participants, many are of poor quality, most have not measured outcomes beyond 6 months, and few have directly compared different active treatment options so that altogether, they offer little evidence to inform clinical decision making. Whilst there is short-term evidence for the effectiveness of some modalities, there is no conclusive evidence of benefit for any of the treatments in the longer term. Although the trials in Table 2 featured treatments 


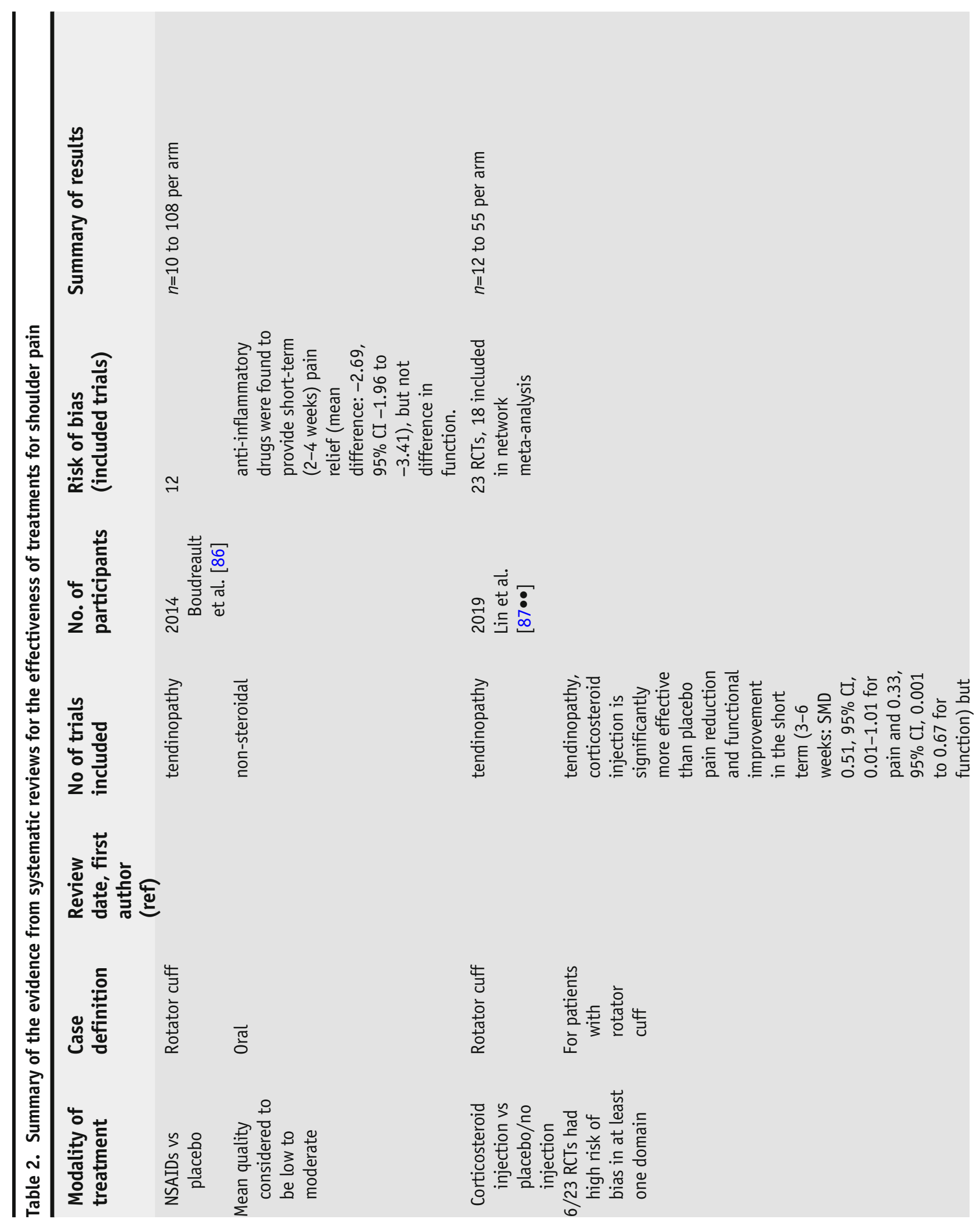




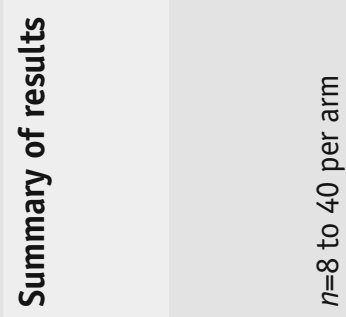

$\frac{\bar{c}}{\frac{0}{2}}$
$\frac{\bar{d}}{\frac{0}{0}}$
$\frac{0}{n}$

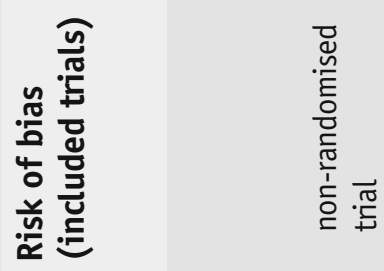

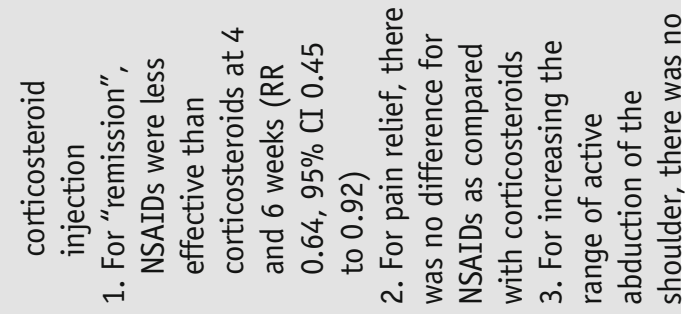

¿ํ.

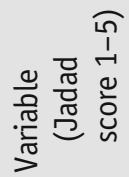

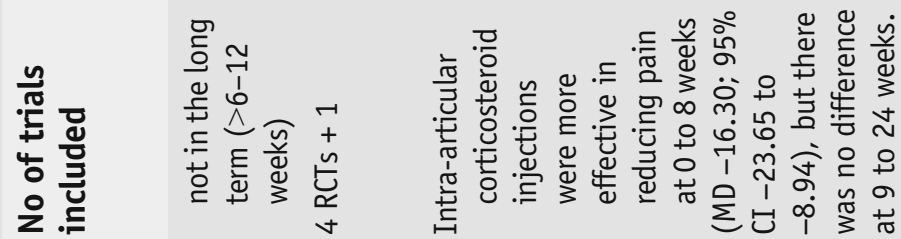

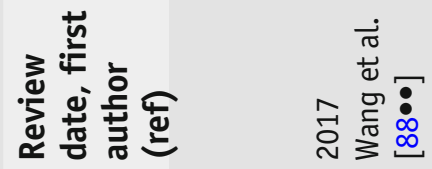

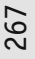

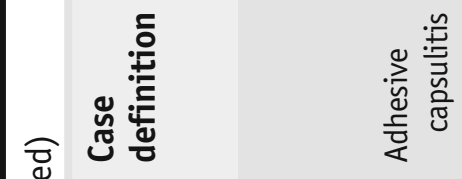

$\frac{n}{\pi}$
$\frac{\pi}{5}$
0

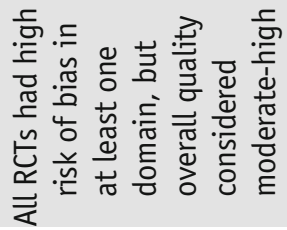

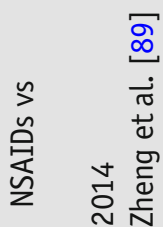




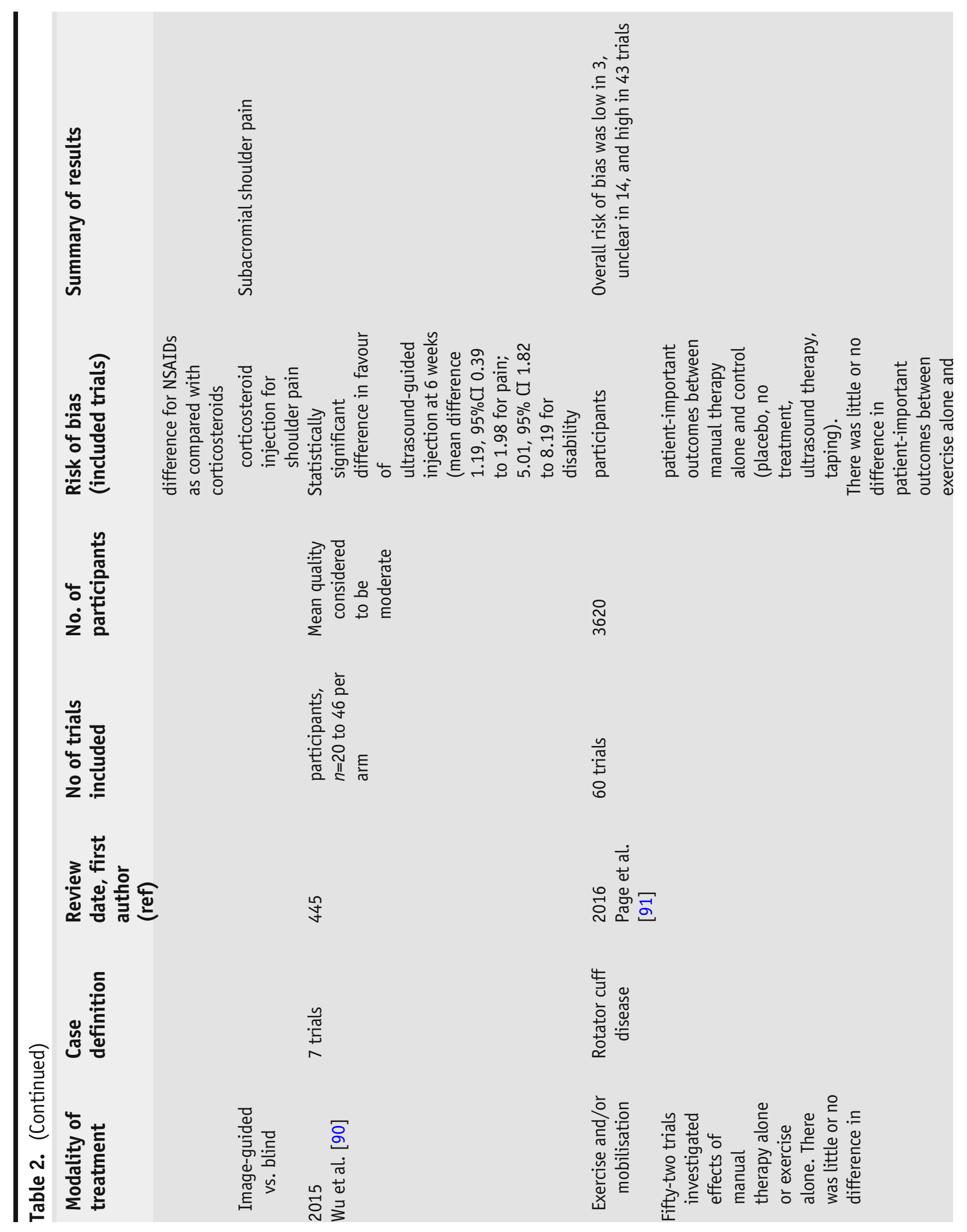




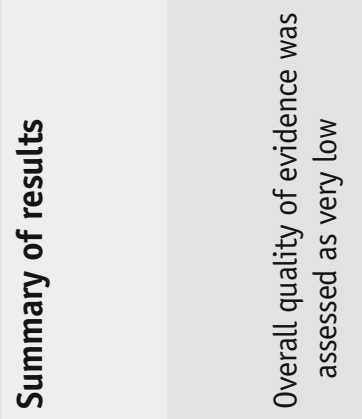

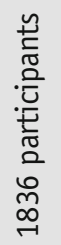

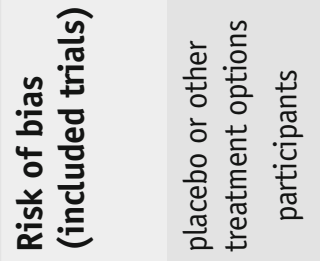

$\underset{m}{\frac{n}{\pi}}$

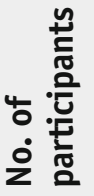

$\stackrel{\infty}{\circ}$

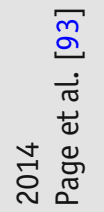

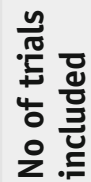

量

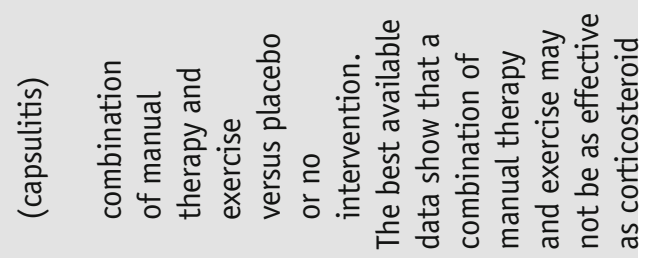

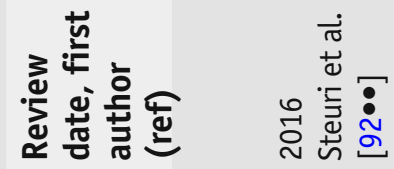

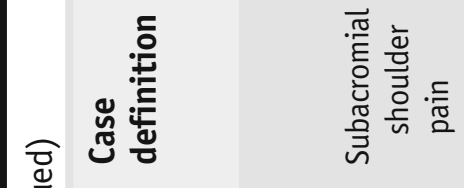
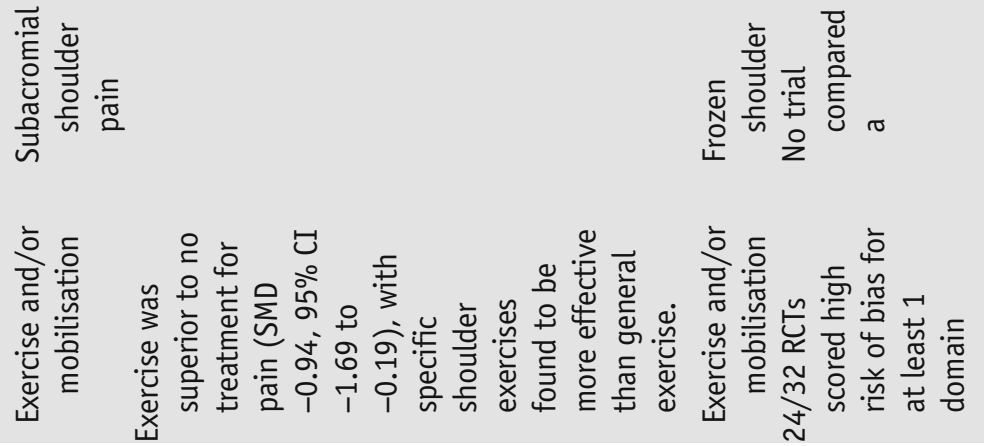

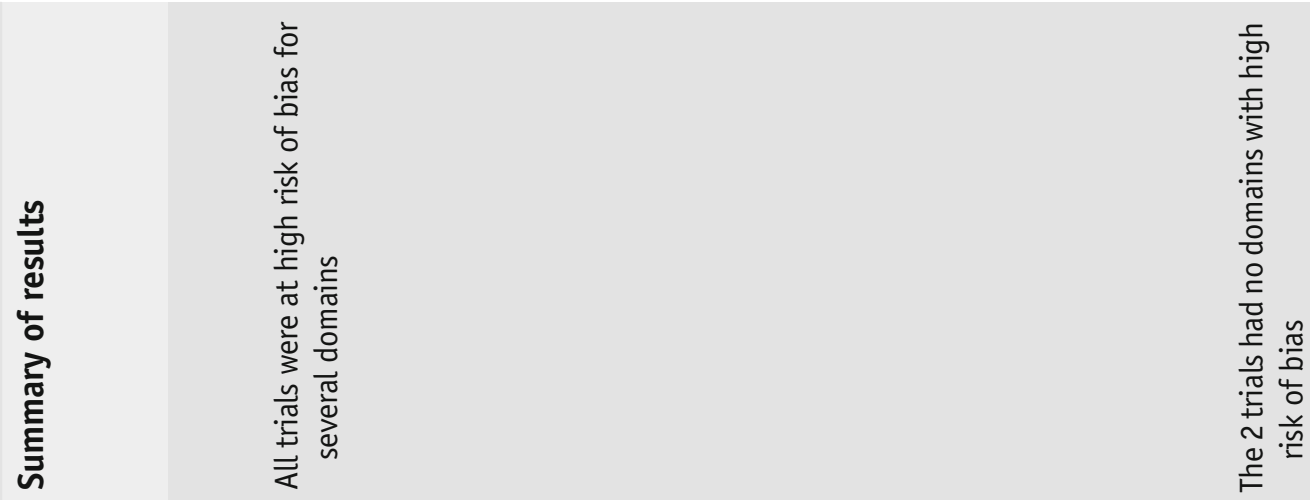

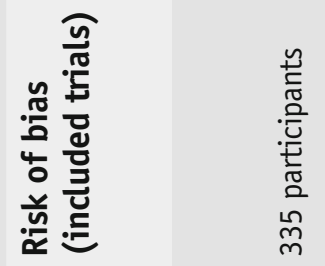

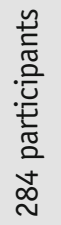

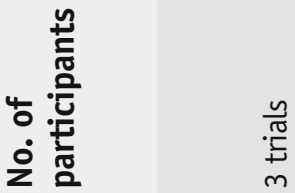

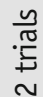

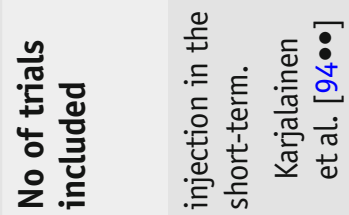

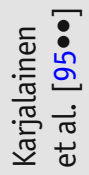

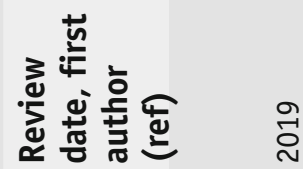

穴
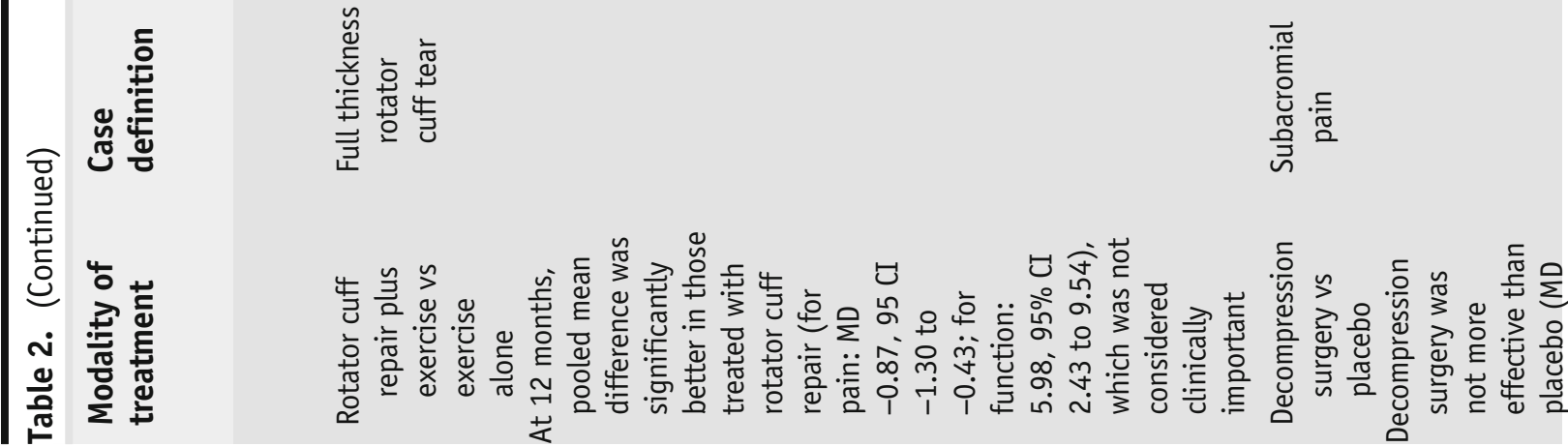


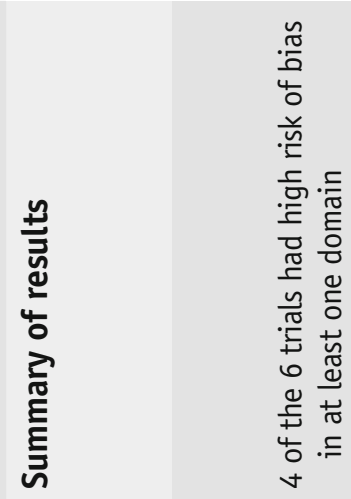

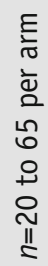

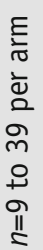

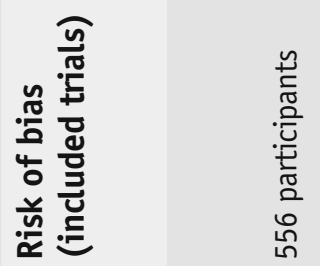

$\frac{y}{0}$
$\stackrel{0}{5}$
$y$

$\frac{n}{n}$
$\frac{\pi}{5}$
$m$

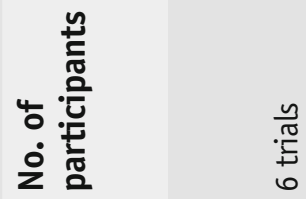

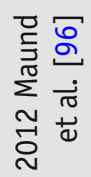

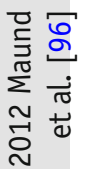

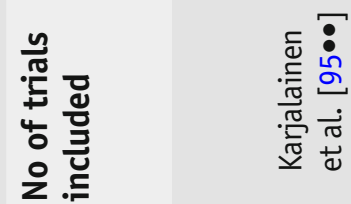

:

㺼

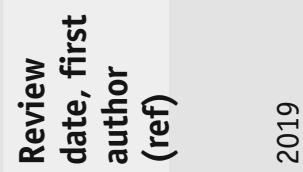

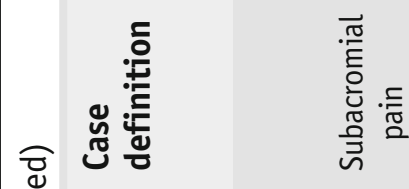

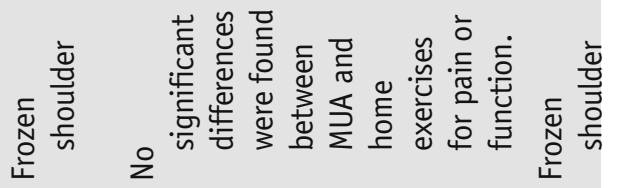

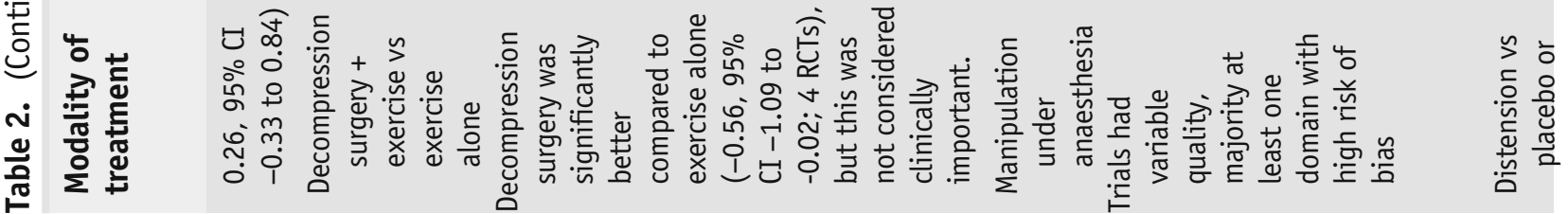




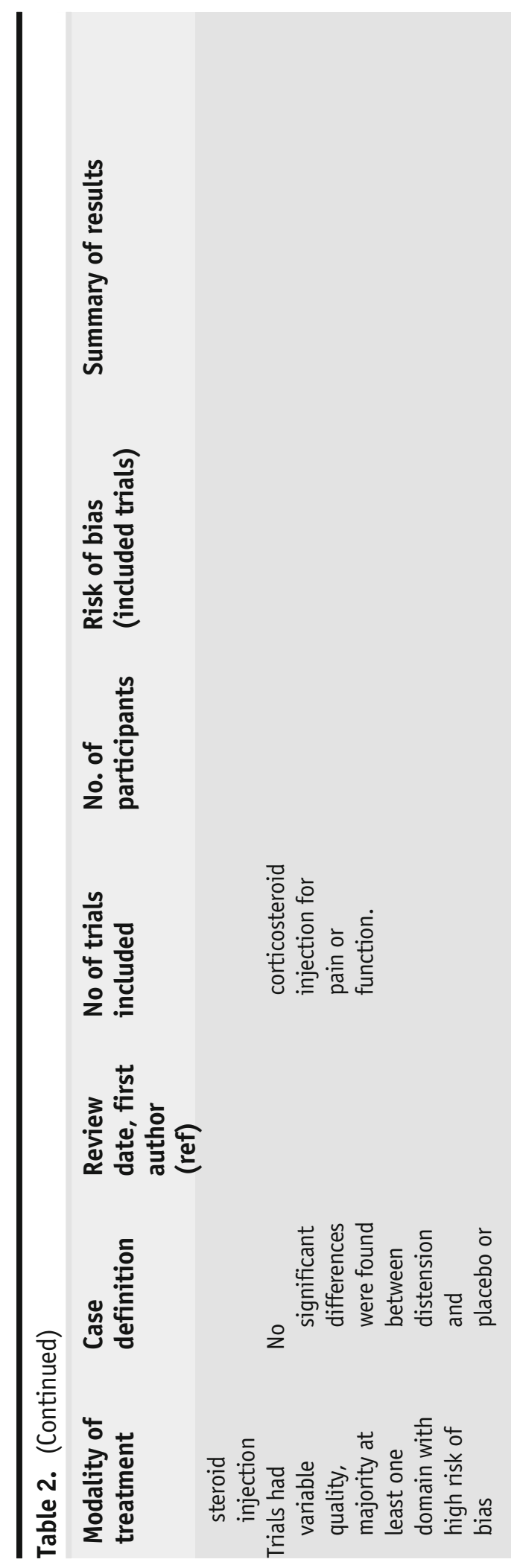


for "shoulder pain", most trials reported results for treatment of rotator cuff tendonitis, adhesive capsulitis (frozen shoulder), and, in one case, calcific tendonitis. This may suggest that patho-anatomical separation of shoulder pain allows separation of types of shoulder pain that will respond to different treatments. Unfortunately, the evidence here is far from convincing: firstly, the evidence suggests that clinicians can only poorly separate patho-anatomical abnormalities with clinical examination $[55,56]$ even when examiners are taught together and using a pre-defined algorithm for diagnosis [55]. Interestingly, in the study by Bamji and colleagues, despite only $46 \%$ agreement about diagnoses, by the far the best agreement was that the optimal treatment would be an intra-articular steroid injection in 19/26 cases [56]. Qualitative research amongst physiotherapists (certified orthopaedic clinical specialists) also showed inconsistency in the labelling of shoulder conditions and little impact of diagnostic labels on treatment decisions [57].

Assuming that localised pathology would respond maximally if treatment is applied to the site, one interesting randomised controlled trial compared the benefit for intra-articular steroid injection injected into the shoulder with that for intra-muscular steroid injection into the gluteal muscle [58]. They were not able to show any significant benefit of the shoulder injection compared with the intramuscular administration. In fact, a Cochrane review of placement of corticosteroid injections with imaging guidance, as compared to without, found no convincing evidence that intra-articular steroid injections placed into the shoulder with imaging guidance were any more effective than those placed using anatomical landmarks and also no more effective than the intra-muscular injection into the gluteal muscle [59]. These findings were borne out by a recently published large RCT which also found no additional benefit for ultrasound-placed as compared with anatomically placed corticosteroid injections [60]. One could hypothesise that these studies collectively suggest that the benefits of corticosteroids are systemic, but an alternative explanation is that the localised patho-anatomical abnormality is only part of the cause of the ongoing shoulder pain which may or may not be corticosteroid-sensitive.

Furthermore, two randomised controlled trials have recently compared outcomes after sub-acromial decompression surgery vs placebo surgery for subacromial shoulder conditions $[61,62]$. Both studies showed that there were no differences between outcomes amongst those who received "real" decompression as compared to placebo surgery, suggesting that a mechanical approach to treating the impingement does not result in significantly better patient outcomes. Likewise, a recent trial amongst patients with frozen shoulder compared two surgical interventions aimed to release the joint capsule (manipulation under anaesthesia and arthroscopic release surgery) with early structured physiotherapy plus steroid injection and found none of the interventions to be clinically superior [63••].

Taken together therefore, there is currently rather limited evidence to suggest that patho-anatomical separation is usefully differentiating diseases with different response to therapies, medical or surgical.

\section{Shoulder pain prognosis}

On the other hand, it could be that separation of shoulder conditions pathoanatomically tells us something about prognosis. In 2011, a Delphi exercise 
took place to achieve consensus about the most important prognostic factors which would predict persistent shoulder pain (less than 50\% improved) 3 months after presenting in primary care [64]. After a systematic review, 46 criteria were considered in the Delphi and the final consensus was that the following 10 factors were most important: duration of pain, catastrophizing of pain, the history of symptoms, fear-avoidance beliefs, presence of neck pain, severity of disability, comorbid mental health, current sickness absence, and presence of multisite pain were the factors which best predicted chronicity [64]. Contemporaneously, a model was derived statistically using the records of almost 600 primary care patients. The statistical model resulted in the following list of factors predicting persistent shoulder pain: sporting injury (yes); longer duration of symptoms; co-existent low back pain; bilateral shoulder pain; functional restriction; other upper limb pain. When tested, both models performed similarly (area under the curve (0.6-0.7)) in correctly assessing prognosis. Notably, neither model considers patho-anatomical factors other than pain at other anatomical sites.

Subsequently, Kooijman and colleagues undertook a comprehensive systematic review of prognostic factors for shoulder pain in 2015 [65]. Between 2003 and 2014, they identified nine cohort studies which considered in total 60 prognostic factors for shoulder pain. Six studies were described by the authors as high-quality and three as low-quality according to their methodological quality assessment. They found convincing evidence that there was no prognostic association with shoulder physical examination findings, including whether or not range of motion was restricted; degree of restriction of motion; muscle strength; or baseline diagnosis of a large rotator cuff tear [65]. Likewise, treatments including physiotherapy and medication prescribed in primary care were also not shown to affect prognosis. In fact, the factors which best predicted poor prognosis were longer pain duration, higher pain intensity, co-existing neck pain, greater disability, and previous shoulder pain [65].

As we have already seen, there are few long-term follow-up studies after intervention but those we have all appear to suggest that most patients remain symptomatic in the medium to long-term, no matter what their starting diagnosis was and whether or not they received active treatment [24]. As argued by Croft et al. [66], the role of diagnosis in clinical practice is challenged by evidence that it does not always benefit patients and that factors other than pathoanatomical classification are important in determining patient outcome. In such cases, a prognostic framework that extends beyond diagnosis and incorporates a wide range of biological, psychological, and social information to predict future patient outcomes, could provide a basis for decision making and potentially more effective and efficient patient care.

\section{Is shoulder pain therefore more like back pain?}

In the early 1990s, based upon a wealth of evidence and primary research into the causes of and treatment for low back pain, the Clinical Standards Advisory Group produced new guidance for the diagnosis and management of low back pain [67]. The guidance suggested that most of low back pain was "simple mechanical back pain" and that our approaches were in danger of over-medicalising a common clinical state and causing or worsening disability, a point which was powerfully 
reiterated by a recent review in the Lancet [68]. Since the 1990s, the approach to low back pain that has been recommended is a triage approach based upon red and yellow flags, minimal use of terminology, minimal investigation (no use of lumbar spine X-ray), and dispensing with the making of "anatomical" diagnoses for the majority $[67,68]$. Although the shoulder pain research field is nowhere near as established as the low back pain literature was in the 1980s, there do appear to be some important parallels developing in the evidence base for shoulder pain.

It is noteworthy therefore that initiatives both in the Netherlands [69••] and the UK $[70 \bullet, 71]$ involve approaching shoulder pain in a way that is more akin to that described above for low back pain. Importantly, both initiatives are focussed in primary care where the vast majority of shoulder pain presents and is managed and a different approach is possibly indicated for the small proportion of people with shoulder pain who reach secondary care. In the Netherlands, guidelines for the primary care management of shoulder pain propose a simple classification of shoulder pain into (i) subacromial shoulder pain (characterised by pain when lifting the arm); (ii) glenohumeral joint problems (characterised by pain and limitation of movement during abduction and rotation); (iii) other conditions, including shoulder pain related to problems of the cervicothoracic spine. Importantly, recommendations regarding treatment and referral are the same for subacromial and glenohumeral conditions, and are guided by the severity of pain, functional limitations, and impact on work and other activities, not by the presumed patho-anatomical diagnoses [69••]. In the UK, colleagues in Keele are investigating use of a single panel of questions for patients presenting with any one of five common musculoskeletal pain conditions (including shoulder pain) $[70 \bullet, 71]$. After exclusion of any red flags, people with musculoskeletal pain are effectively "triaged" for the presence of widespread pain, and adverse psychological and behavioural traits that are likely to be associated with a poorer prognosis. The subsequent management of the pain is tailored accordingly. This approach has already shown promise for patients presenting with low back pain in primary care [72], and the trial of this approach for pain at other sites is underway [70•].

\section{Conclusion}

There is plenty of evidence that our current approach to shoulder pain is limited in its success. This is a common, costly problem which increases with age and, as longevity increases, is set to cause more disability. For the majority of cases of shoulder pain, we call for a new approach emphasising de-medicalisation, supporting people to manage their own symptoms and considering chronic shoulder pain as a chronic condition in its own right, much as is widely accepted for other chronic pain conditions such as low back pain.

\section{Declarations}

\section{Conflict of Interest}

Karen Walker-Bone declares that she has no conflict of interest. Danielle van der Windt declares that she has no conflict of interest. 


\section{Human and Animal Rights and Informed Consent}

This article does not contain any studies with human or animal subjects performed by any of the authors.

Open Access This article is licensed under a Creative Commons Attribution 4.0 International License, which permits use, sharing, adaptation, distribution and reproduction in any medium or format, as long as you give appropriate credit to the original author(s) and the source, provide a link to the Creative Commons licence, and indicate if changes were made. The images or other third party material in this article are included in the article's Creative Commons licence, unless indicated otherwise in a credit line to the material. If material is not included in the article's Creative Commons licence and your intended use is not permitted by statutory regulation or exceeds the permitted use, you will need to obtain permission directly from the copyright holder. To view a copy of this licence, visit http://creativecommons.org/licenses/by/4.0/.

\section{References and Recommended Reading}

Papers of particular interest, published recently, have been highlighted as:

- Of importance

$\bullet \quad$ Of major importance

1. Luime JJ, Koes BW, Hendriksen IJ, Burdorf A, Verhagen $\mathrm{AP}$, Miedema HS, et al. Prevalence and incidence of shoulder pain in the general population; a systematic review. Scand J Rheumatol. 2004;33(2):73-81.

2. Allander E. Prevalence, incidence and remission rates of some common rheumatic diseases and syndromes. Scand J Rheumatol. 1974;3(3):145-53.

3. Chard MD, Hazelman R, Hazelman BL, et al. Shoulder disorders in the elderly: a community survey. Arthritis Rheum. 1991;34:766-9.

4. Andersson HI, Ejlertsson G, Leden I, Rosenberg C. Chronic neck pain in a geographically defined general population: studies of differences in age, gender, social class and pain localisation. Clin J Pain. 1993;9:174-82.

5. Walker-Bone K, Reading I, Coggon D, et al. The anatomical pattern and determinants of pain in the neck and upper limbs: an epidemiologic study. Pain. 2004;109:45-51.

6. Greving K, Dorrestijn O, Winters JC, Groenhof F, van der Meer K, Stevens M, et al. Incidence, prevalence, and consultation rates of shoulder complaints in general practice. Scand J Rheumatol. 2012;41(2):150-5.

7. Jordan KP, Kadam UT, Hayward R, Porcheret M, Young C, Croft P. Annual consultation prevalence of regional musculoskeletal problems in primary care: an observational study. BMC Musculoskelet Disord. 2010;11:144.

8. Buchbinder R, Staples MP, Shanahan EM, Roos JF. General practitioner management of shoulder pain in comparison with rheumatologist expectation of care and best evidence: an Australian national survey. PLoS One. 2013;8(4):e61243.

9. $\quad$ Artus M, van der Windt DA, Afolabi EK, Buchbinder R, Chesterton LS, Hall A, et al. Management of shoulder pain by UK general practitioners (GPs): a national survey. BMJ Open. 2017;7(6):e01571.
This paper describes the heterogeneity of management of shoulder pain in general practice.

10. Croft P, Pope D, Silman A, Primary Care Rheumatology Society Shoulder Study Group. The clinical course of shoulder pain: prospective cohort study in primary care. BMJ. 1996;313(7057):601-2.

11. Pope DP, Silman AJ, Cherry NMC, et al. Association of occupational physical demands and psychosocial working environment with disabling shoulder pain. Ann Rheum Dis. 2001;60:852-8.

12. Kuijpers T, van der Windt DAWM, van der Heijden GJMG, Bouter LM. Systematic review of prognostic cohort studies on shoulder disorders. Pain. 2004;109:420-31.

13. Virta L, Joranger P, Brox JI, Eriksson R. Costs of shoulder pain and resource use in primary health care: a costof-illness study in Sweden. BMC Musculoskelet Disord. 2012;13:17.

14. Kuijpers T, van der Windt DAWM, van der Heijden GJMG, et al. A prediction rule for shoulder pain related sick leave: a prospective cohort study. BMC Musculoskelet Disord. 2006;7:97.

15. Nyman T, Grooten WJA, Wiktorin C, et al. Sickness absence and concurrent low back and neck-shoulder pain: results from the MUSIC-Norrtalje study. Eur Spine J. 2007;16:631-8.

16. Holtermann A, Hansen JV, Burr H, Sogaard K. Prognostic factors for long-term sickness absence among employees with neck-shoulder and low-back pain. Scand J Work Environ Health. 2010;36:34-41.

17. Palmer KT, Harris EC, Linaker $\mathrm{C}$, et al. Effectiveness of community- and workplace-based interventions to manage musculoskeletal-related sickness absence and job loss: a systematic review. Rheumatol. 2012;51:230-42. 
18. Chard MD, Hazleman R, Hazleman BL, King RH, Reiss BB. Shoulder disorders in the elderly: a community survey. Arthritis Rheum. 1991;34(6):766-9.

19. Miranda H, Punnett L, Viikari-Juntura E, et al. Physical work and chronic shoulder disorder. Results of a prospective population-based study. Ann Rheum Dis. 2008;67:218-23.

20. Bernard BP, editor. Musculoskeletal disorders (MSDs) and workplace factors. Cincinnati $(\mathrm{OH})$ : US Department of Health and Human Services; 1997.

21. Silverstein BA, Bao SS, Fan ZJ, et al. Rotator cuff syndrome: personal, work-related psychosocial and physical load factors. J Occup Environ Med. 2008;50:1062-76.

22. Van der Windt DAWM, Thomas E, Pope DP, et al. Occupational risk factors for shoulder pain: a systematic review. Occup Environ Med. 2000;57:433-42.

23. Codman EA. The shoulder. Boston: Todd; 1934.

24. Croft P. Measuring up to shoulder pain. Ann Rheum Dis. 1998;57:65-6.

25. Cyriax JH. Diagnosis of soft tissue lesions. London, Balliere Tindall: Textbook of Orthopaedic Medicine; 1982.

26. Roy JS, Braen C, Leblond J, Desmeules F, Dionne CE, MacDermid JC, et al. Diagnostic accuracy of ultrasonography, MRI and MR arthrography in the characterisation of rotator cuff disorders: a systematic review and meta-analysis. Br J Sports Med. 2015;49:1316-28.

27. Ottenheijm RP, Jansen MJ, Staal JB, van den Bruel A, Weijers RE, de Bie RA, et al. Accuracy of diagnostic ultrasound in patients with suspected subacromial disorders: a systematic review and meta-analysis. Arch Phys Med Rehabil. 2010;91:1616-25.

28. Lenza M, Buchbinder R, Takwoingi Y, Johnston RV, Hanchard NCA, Faloppa F. Magnetic resonance imaging, magnetic resonance arthrography and ultrasonography for assessing rotator cuff tears in people with shoulder pain for whom surgery is being considered. Cochrane Database Syst Rev. 2013;9:1465-858.

29. Curry EJ, Matzkin EE, Dong Y, Higgins LD, Katz JN, Jain MB. Structural characteristics are not associated with pain and function in rotator cuff tears. Orthop J Sports Med. 2015;3(5):2325967115584596.

30. Milgrom C, Schaffler M, Gilbert S, van Holsbeeck M. Rotator-cuff changes in asymptomatic adults. The effect of age, hand dominance and gender. J Bone Joint Surg (Br). 1995; 77:296-8.

31. Girish G, Lobo LG, Jacobson JA, Morag Y, Miller B, Jamadar DA. Ultrasound of the shoulder: asymptomatic findings in men. Am J Roentgenol.

2011;197:W713-9.

32. Frost $\mathrm{P}$, Andersen JH, Lundorf E. Is supraspinatus pathology as defined by magnetic resonance imaging associated with clinical sign of shoulder impingement? J Shoulder Elb Surg. 1999;8(6):565-8.

33. Unruh KP, Kuhn JE, Sanders R, An Q, Baumgarten KM, Bishop JY, et al. The duration of symptoms does not correlate with rotator cuff tear severity or other patientrelated features: a cross-sectional study of patients with atraumatic, full-thickness rotator cuff tears. J Shoulder Elb Surg. 2014;23(7):1052-8.

34. Dunn WR, Kuhn JE, Sanders R, An Q, Baumgarten KM, Bishop JY, et al. Symptoms of pain do not correlate with rotator cuff tear severity: a cross-sectional study of 393 patients with a symptomatic atraumatic fullthickness rotator cuff tear. J Bone Joint Surg Am. 2014;96(10):793-800.

35. Ottenheijm RPG, Cals JWL, Winkens B, et al. Ultrasound imaging to tailor the treatment of acute shoulder pain: a randomised controlled trial in general practice. BMJ Open. 2016;6:e011048.

36.• Tran G, Cowling P, Smith T, Bury J, Lucas A, Barr A, et al. What imaging-detected pathologies are associated with shoulder symptoms and their persistence? A systematic literature review. Arthritis Care Res. 2018;70:1169-8.

This paper summarises the poor relationship between imaging findings and shoulder pain prognosis.

37. Tran G, Hensor EMA, Ray A, Kingsbury SR, O'Connor P, Conaghan PG. Ultrasound-detected pathologies cluster into groups with different clinical outcomes: data from 3000 community referrals for shoulder pain. Arthritis Res Ther. 2017;19:30. https://doi.org/10. 1186/s13075-017-1235-y.The authors use statistical techniques to derive clusters from ultrasound scans and then explore the clinical treatment offered to a subset of patients showing marked heterogeneity.

38. Sher JS, Uribe JW, Posada A, Murphy BJ, Zlatkin MB. Abnormal findings on magnetic resonance images of asymptomatic shoulders. J Bone Joint Surg Am. 1995;77:10-5.

39. Kamaleri $Y$, et al. Localized or widespread musculoskeletal pain: does it matter? Pain. 2008;138(1):41-6.

40. Garland EL. Pain processing in the human nervous system: a selective review of nociceptive and biobehavioral pathways. Prim Care. 2012;39(3):561-71.

41. Blackwell DL, Lucas JW, Clarke TC. Summary health statistics for U.S. adults: National Health Interview Survey, 2012. National Center for Health Statistics. Vital Health Stat. 2014;10(260).

42. Patel KV, Guralnik JM, Dansie EJ, Turk DC. Prevalence and impact of pain among older adults in the United States: findings from the 2011 National Health and Aging Trends Study. Pain. 2013;154(12):2649-57.

43. Coggon D, Ntani G, Palmer KT, et al. Patterns of multisite pain and associations with risk factors. Pain. 2013;154(9):1769-77.

44.• Yabe Y, Hagiwara Y, Sekiguchi T, et al. Musculoskeletal pain in other body sites is associated with new-onset low back pain: a longitudinal study among survivors of the great East Japan earthquake. BMC Musculoskelet Disord. 2020;21(1):22.

This paper emphasises the importance of pain at other musculoskeletal sites on incident musculoskeletal pain.

45. Hallman DM, Holtermann A, Björklund M, Gupta N, Nørregaard Rasmussen CD. Sick leave due to musculoskeletal pain: determinants of distinct trajectories over 1 year. Int Arch Occup Environ Health. 
2019;92(8):1099-108. https://doi.org/10.1007/ s00420-019-01447-yHallman and colleagues demonstrate the relevance of multisite musculoskeletal pain to sickness absence.

46. Fernandes RCP, De Cássia PR, Burdorf A. Associations of multisite pain with healthcare utilization, sickness absence and restrictions at work. Int Arch Occup Environ Health. 2016;89(7):1039-46.

47. Beneciuk JM, Lentz TA, He Y, Wu SS, George SZ. Prediction of persistent musculoskeletal pain at 12 months: a secondary analysis of the Optimal Screening for Prediction of Referral and Outcome (OSPRO) Validation Cohort Study. Phys Ther. 2018;98(5):290-30.

This paper shows the importance of pain at other musculoskeletal sites in predicting persistence of musculoskeletal pain.

48. Van der Windt DAWM, Koes BW, Boeke AJP, Devillé WLJM, De Jong BA, Bouter LM. Shoulder disorders in general practice: prognostic indicators of outcome. Br J Gen Pract. 1996;46:519-23.

49. Kuijpers T, Van der Windt DAWM, Boeke AJP, Twisk JWR, Vergouwe Y, Bouter LM, et al. Clinical prediction rules for the prognosis of shoulder pain in general practice. Pain. 2006;120:276-85.

50. Bot SDM, Van der Waal JM, Terwee CB, Van der Windt DAWM, Scholten RJPM, Bouter LM, et al. Predictors of outcome in neck and shoulder symptoms: a cohort study in general practice. Spine. 2005;30:459-70.

51. Keijsers E, Feleus A, Miedema HS, Koes BW, BiermaZeinstra SM. Psychosocial factors predicted nonrecovery in both specific and nonspecific diagnoses at arm, neck, and shoulder. J Clin Epidemiol. 2010;63(12):1370-9.

52. Coronado RA, Simon CB, Valencia C, George SZ. Experimental pain responses support peripheral and central sensitization in patients with unilateral shoulder pain. Clin J Pain. 2014;30(2):143-51.

53.• J-l L, Yan C-Q, Wang X, Zhang S, Zhang N, Hu S-Q, et al. Brain functional alternations of the pain-related emotional and cognitive regions in patients with chronic shoulder pain. J Pain Res. 2020;13:575-8.

This paper evaluates functional MRI in the brain amongst patients with shoulder pain.

54. Jain NB, Ayers GD, Fan R, Kuhn JE, Baumgarten KM, Matzkin EE, et al. Predictors of pain and functional outcomes after operative treatment for rotator cuff tears. J Shoulder Elb Surg. 2018;27(8):1393-40.

This paper showed that none of socio-demographic characteristics, MRI findings, shoulder strength, or surgical techniques/ performance of adjuvant surgical procedures predicted postoperative pain or function but that pre-operative beliefs predicted better functional outcomes.

55. De Winter AF, Jans MP, Scholten RJ, Devillé W, van Schaardenburg D, Bouter LM. Diagnostic classification of shoulder disorders: inter-observer agreement and determinants of disagreement. Ann Rheum Dis. 1999;58(5):272-7.

56. Bamji AN, Erhardt CC, Price TR, Williams PL. The painful shoulder: can consultants agree? $\mathrm{Br} \mathrm{J}$ Rheumatol. 1996;35(11):1172-4.
57. Miller-Spoto M, Gombatto SP. Diagnostic labels assigned to patients with orthopedic conditions and the influence of the label on selection of interventions: a qualitative study of orthopaedic clinical specialists. Phys Ther. 2014;94(6):776-91.

58. Ekeberg OM, Bautz-Holter E, Tveita EK, Juel NG, Kvalheim S, Brox JI, et al. Subacromial ultrasound guided or systemic steroid injection for rotator cuff disease: randomised double blind study. BMJ. 2009;338:a3112.

59. Buchbinder R, Green S, Youd JM. Corticosteroid injections for shoulder pain. Cochrane Database Syst Rev 2003, Issue 1. Art. No.: CD004016. DOI: https://doi. org/10.1002/14651858.CD004016

60. Paskins Z, Hughes G, Myers H, et al. A randomised controlled trial of the clinical and cost-effectiveness of ultrasound-guided intra-articular corticosteroid and local anaesthetic injections: the hip injection trial (HIT) protocol. BMC Musculoskelet Disord. 2018;19(1):218.

61. Beard DJ, Rees JL, Cook JA, et al. Arthroscopic subacromial decompression for subacromial shoulder pain (CSAW): a multicentre, pragmatic, parallel group, placebo-controlled, three-group, randomised surgical trial. Lancet. 2018;391(10118):329-38.

62. Paavola M, Malmivaara A, Taimela S, et al. Subacromial decompression versus diagnostic arthroscopy for shoulder impingement: randomised, placebo surgery controlled clinical trial. BMJ. 2018;362:k2860.

63.• Rangan A, Brealey SD, Keding A, Corbacho B, Northgraves M, Kottam L, et al. Management of adults with primary frozen shoulder in secondary care (UK FROST): a multicentre, pragmatic, three-arm, superiority randomised clinical trial. Lancet. 2020;396(10256):977-8.

This is a recent RCT exploring the effectiveness of management approaches for frozen shoulder.

64. Vergouw D, Heymans MW, de Vet HC, van der Windt DA, van der Horst HE. Prediction of persistent shoulder pain in general practice: comparing clinical consensus from a Delphi procedure with a statistical scoring system. BMC Fam Pract. 2011;12:63.

65. Kooijman MK, Barten DJ, Swinkels IC, Kuijpers T, de Bakker D, Koes BW, et al. Pain intensity, neck pain and longer duration of complaints predict poorer outcome in patients with shoulder pain-a systematic review. BMC Musculoskelet Disord. 2015;16:288.

66. Croft P, Altman DG, Deeks JJ, Dunn KM, Hay AD, Hemingway $\mathrm{H}$, et al. The science of clinical practice: disease diagnosis or patient prognosis? Evidence about "what is likely to happen" should shape clinical practice. BMC Med. 2015;13(1):20.

67. Clinical Standards Advisory Group (CSAG). Back pain. London: HMSO; 1994.

68. Buchbinder R, van Tulder M, Oberg B, Costa LM, Woolf A, Schoene M, et al. Low back pain: a call for action. Lancet. 2018;391:2384-8.

69.• Damen GJ, Koel G, Kuijpers T, Ottenheijm RP, Schellingerhout JM, Van den Donk M, et al. NHG Standaard Schouderklachten (M08). Utrecht: NHG; 2019. 
Current Netherlands guidance for the management of shoulder pain.

70. Hill J, Garvin S, Chen Y, Cooper V, Wathall S, Bartlam $\mathrm{B}$, et al. Computer-based stratified primary care for musculoskeletal consultations compared with usual care: study protocol for the STarT MSK Cluster Randomized Controlled Trial. JMIR Res Protoc. 2020;9(7):e1793.

Protocol for the STarT MSK randomised controlled trial which is currently underway.

71. Hill JC, Garvin S, Chen Y, Cooper V, Wathall S, Saunders B, et al. Stratified primary care versus nonstratified care for musculoskeletal pain: findings from the STarT MSK feasibility and pilot cluster randomized controlled trial. BMC Fam Pract. 2020;21(1):30.

72. Hill JC, Whitehurst DG, Lewis M, et al. Comparison of stratified primary care management for low back pain with current best practice (STarT Back): a randomised controlled trial. Lancet. 2011;378:1560-71.

73. Sansone V, Bonora C, Boria P, Meroni R. Women performing repetitive work: is there a difference in the prevalence of shoulder pain and pathology in supermarket cashiers compared to the general population? Int J Occup Med Environ Health. 2014;27:722-35.

74. Luime JL, Kuiper J, Koes BW, et al. Work-related risk factors for the incidence and recurrence of shoulder and neck complaints among nursing-home and elderly-care workers. Scand J Work Environ Health. 2004;30:279-86.

75. Ryall C, Coggon D, Peveler R, et al. A prospective cohort study of arm pain in primary care and physiotherapy- prognostic determinants. Rheumatology. 2007;46:508-15.

76. Shah KM, Clark BR, McGill JB, Mueller MJ. Upper extremity impairments, pain and disability in patients with diabetes mellitus. Physiotherapy.

2015;101(2):147-54.

77. Anwer S, Alghadir A. Incidence, prevalence, and risk factors of hemiplegic shoulder pain: a systematic review. Int J Environ Res Public Health. 2020;17(14):4962.

78. Nahit ES, Hunt IM, Lunt M, Dunn G, Silman AJ, Macfarlane GJ. Effects of psychosocial and individual psychological factors on the onset of musculoskeletal pain: common and site-specific effects. Ann Rheum Dis. 2003;62:755-60.

79. Bovenzi M. A prospective cohort study of neck and shoulder pain in professional drivers. Ergonomics. 2014;7:1-14

80. Sarquis LM, Coggon D, Ntani G, et al. Classification of neck/shoulder pain in epidemiological research: a comparison of personal and occupational characteristics, disability, and prognosis among 12,195 workers from 18 countries. Pain. 2016;157(5):1028-36.

81. Beach J, Senthilselvan A, Cherry N. Factors affecting workrelated shoulder pain. Occup Med. 2012;62:451-4.

82. Andersen JH, Haahr JP, Frost P. Risk factors for more severe regional musculoskeletal symptoms. A two-year prospective study of a general working population. Arthritis Rheum. 2007;56(4):1355-64.

83. Harkness EF, Macfarlane GJ, Nahit ES, et al. Mechanical and psychosocial factors predict new onset shoulder pain: a prospective cohort study of newly employed workers. Occup Environ Med. 2003;60:850-7.

84. Leclerc A, Chastang J-F, Niedhammer I, et al. Incidence of shoulder pain in repetitive work. Occup Environ Med. 2004;61:39-44.

85. Descatha A, Chastang JF, Cyr D, Leclerc A, Roquelaure Y, Evanoff B. Do workers with self-reported symptoms have an elevated risk of developing upper extremity musculoskeletal disorders three years later? Occup Environ Med. 2008;65:205-7.

86. Boudreault J, Desmeules F, Roy JS, Dionne C, Frémont P, Macdermid JC. The efficacy of oral non-steroidal anti-inflammatory drugs for rotator cuff tendinopathy: a systematic review and meta-analysis. J Rehabil Med. 2014;46(4):294-306.

87.• Lin MT, Chiang CF, Wu CH, Huang YT, Tu YK, Wang TG. Comparative effectiveness of injection therapies in rotator cuff tendinopathy: a systematic review, pairwise and network meta-analysis of randomized controlled trials. Arch Phys Med Rehabil. 2019;100(2):336-349.e1.

This paper provides a meta-analysis of the effectiveness of injected treatments for rotator cuff tendinopathy.

88.• Wang W, Shi M, Zhou C, Shi Z, Cai X, Lin T, et al. Effectiveness of corticosteroid injections in adhesive capsulitis of shoulder: a meta-analysis. Medicine (Baltimore). 2017;96(28):e752.

This is a meta-analysis and systematic review of the RCT evidence for effectiveness of corticosteroid injections for the treatment of frozen shoulder.

89. Zheng XQ, Li K, Wei YD, Tie HT, Yi XY, Huang W. Nonsteroidal anti-inflammatory drugs versus corticosteroid for treatment of shoulder pain: a systematic review and meta-analysis. Arch Phys Med Rehabil. 2014;95(10):1824-31.

90. Wu T, Song HX, Dong Y, Li JH. Ultrasound-guided versus blind subacromial-subdeltoid bursa injection in adults with shoulder pain: a systematic review and meta-analysis. Semin Arthritis Rheum. 2015;45:374-8.

91. Page MJ, Green S, McBain B, Surace SJ, Deitch J, Lyttle $\mathrm{N}$, et al. Manual therapy and exercise for rotator cuff disease. Cochrane Database Syst Rev. 2016;6:CD012224.

92.• Steuri R, Sattelmayer M, Elsig S, Kolly C, Tal A, Taeymans J, et al. Effectiveness of conservative interventions including exercise, manual therapy and medical management in adults with shoulder impingement: a systematic review and meta-analysis of RCTs. Br J Sports Med. 2017;51(18):1340-.

This is the most up to date review of the evidence for the effectiveness of non-injection therapies for patients with shoulder impingement.

93. Page MJ, Green S, Kramer S, Johnston RV, McBain B, Chau M, Buchbinder R. Manual therapy and exercise for adhesive capsulitis (frozen shoulder). Cochrane 
Database Syst Rev. 2014;(8):CD011275. https://doi. org/10.1002/14651858.CD011275.

94.• Karjalainen TV, Jain NB, Heikkinen J, Johnston RV, Page CM, Buchbinder R. Surgery for rotator cuff tears. Cochrane Database Syst Rev. 2019;12:CD01350.

This Cochrane review describes the evidence from RCTs about the effectiveness of surgical treatment for rotator cuff disease.

95.• Karjalainen TV, Jain NB, Page CM, Lähdeoja TA, Johnston RV, Salamh P, et al. Subacromial decompression surgery for rotator cuff disease. Cochrane Database Syst Rev. 2019;1:CD005619 This Cochrane review presents the evidence of effectiveness of surgical sub-acromial decompression surgery for rotator cuff disease.
96. Maund E, Craig D, Suekarran S, Neilson A, Wright K, Brealey S, et al. Management of frozen shoulder: a systematic review and cost-effectiveness analysis. Health Technol Assess. 2012;16(11):1-264. https:// doi.org/10.3310/hta16110.

\section{Publisher's Note}

Springer Nature remains neutral with regard to jurisdictional claims in published maps and institutional affiliations. 